\title{
Effects of the addition of functional electrical stimulation to ground level gait training with body weight support after chronic stroke
}

\section{Efeitos da adição da estimulação elétrica funcional ao treino de marcha em piso fixo com suporte parcial de peso após acidente vascular encefálico crônico}

\author{
Christiane L. Prado-Medeiros', Catarina O. Sousa', Andréa S. Souza', Márcio R. Soares', Ana M. F. Barela², Tania F. Salvini'
}

\begin{abstract}
Background: The addition of functional electrical stimulation (FES) to treadmill gait training with partial body weight support (BWS) has been proposed as a strategy to facilitate gait training in people with hemiparesis. However, there is a lack of studies that evaluate the effectiveness of FES addition on ground level gait training with BWS, which is the most common locomotion surface. Objective: To investigate the additional effects of commum peroneal nerve FES combined with gait training and BWS on ground level, on spatialtemporal gait parameters, segmental angles, and motor function. Methods: Twelve people with chronic hemiparesis participated in the study. $A n A_{1}-B-A_{2}$ design was applied. $A_{1}$ and $A_{2}$ corresponded to ground level gait training using $B W S$, and $B$ corresponded to the same training with the addition of FES. The assessments were performed using the Modified Ashworth Scale (MAS), Functional Ambulation Category (FAC), Rivermead Motor Assessment (RMA), and filming. The kinematics analyzed variables were mean walking speed of locomotion; step length; stride length, speed and duration; initial and final double support duration; single-limb support duration; swing period; range of motion (ROM), maximum and minimum angles of foot, leg, thigh, and trunk segments. Results: There were not changes between phases for the functional assessment of RMA, for the spatial-temporal gait variables and segmental angles, no changes were observed after the addition of FES. Conclusion: The use of FES on ground level gait training with BWS did not provide additional benefits for all assessed parameters.

Article registered in the ClinicalTrials.gov under the number NCT 01106755.
\end{abstract}

Keywords: stroke; physical therapy; rehabilitation; intervention; kinematics.

\section{Resumo}

Contextualização: A adição da estimulação elétrica funcional (EEF) ao treino de marcha em esteira, com sistema de suporte parcial de peso corporal (SPPC), tem sido proposta como estratégia para melhorar a marcha em hemiparéticos. Entretanto, nenhum estudo verificou a eficácia da adição da EEF ao treino de marcha com SPPC em piso fixo, a superfície mais habitual de locomoção. Objetivo: Investigar os efeitos da adição da EEF do nervo fibular comum, ao treino de marcha com SSPC, em piso fixo, sobre os parâmetros espaço-temporais da marcha, ângulos segmentares e função motora. Métodos: Participaram do estudo 12 hemiparéticos crônicos. $\mathrm{O}$ sistema adotado foi o $\mathrm{A}_{1}-\mathrm{B}-\mathrm{A}_{2}$. $\mathrm{A}_{1}$ e $\mathrm{A}_{2}$ corresponderam ao treino em piso fixo com SPPC, e $\mathrm{B}$, ao mesmo treino, associado à EEF. As avaliações foram realizadas por meio da Escala de Ashworth Modificada (EAM), da Categoria de Deambulação Funcional (CDF), da Avaliação Motora de Rivermead (AMR) e de filmagens. As variáveis cinemáticas analisadas foram: velocidade média de locomoção; comprimento do passo; comprimento, velocidade e duração da passada; duração dos períodos de apoio duplo inicial e final, apoio simples e balanço; ângulos máximos e mínimos e amplitude de movimento (ADM) dos segmentos pé, perna, coxa e tronco. Resultados: Na AMR, não houve alterações entre as fases. Para as variáveis espaço-temporais e ângulos segmentares, não houve nenhuma alteração após a adição da EEF. Conclusão: A adição da EEF ao treino de marcha em piso fixo com SPPC não promoveu melhora adicional nos parâmetros mensurados. Artigo registrado no ClinicalTrials. gov sob o número NCT 01106755

Palavras-chave: acidente vascular encefálico; fisioterapia; reabilitação; intervenção; cinemática.

Received: 01/20/2011 - Revised: 05/11/2011 - Accepted: 08/01/2011

Physical Therapy Department, Universidade Federal de São Carlos (UFSCar), São Carlos, SP, Brazil

${ }^{2}$ Institute of Physical Activity and Sport Science, Universidade Cruzeiro do Sul, São Paulo, SP, Brazil

Correspondence to: Christiane Lanatovitz Prado Medeiros, Laboratório de Plasticidade Muscular, Departamento de Fisioterapia, Universidade Federal de São Carlos, Rodovia Washington

Luis, km 235, CEP: 13565-905, São Carlos, SP, Brasil, e-mail: medeirosclp@gmail.com 


\section{Introduction $: \because$.}

Stroke is a global public health problem ${ }^{1,2}$. Stroke patients present difficulties in performing functional tasks, which impairs their independence on daily activities. Among those tasks, gait is the most impaired one. For that reason, the major goal in a post-stroke rehabilitation program is the walking ability recovery ${ }^{3}$.

The use of a harness attached to a body weight support (BWS) has been used to assist gait training. BWS has been combined with a treadmill, which stimulates rhythmic and repetitive steps in attempt to provide symmetry between limbs and spatial-temporal gait improvements ${ }^{4-7}$. BWS supports a percentage of body weight, allowing patients to endure the rest of their weight easily; therefore, knee collapse or excessive hip flexion during the affected single-limb stance are avoided ${ }^{4,6}$. BWS also provides better balance control, and reduces the risk of falls ${ }^{8}$. Recently, the BWS on a treadmill has also been used combined with functional electrical stimulation (FES), showing gait improvements ${ }^{9-13}$.

The first FES system was implemented by Liberson et al. ${ }^{14}$ to promote the drop foot correction. Electrical signs activate peripheral nerves and control voluntary movements. This technique makes use of afferent feedback during muscle contraction, a process in which the patient's help may maximize motor relearning during active training of repeated movements ${ }^{15,16}$. Thus, the FES of the common peroneal nerve would be able to favor dorsiflexion and eversion movements of the paretic ankle.

In a recent study, Lindquist et al. ${ }^{13}$ evaluated gait training on a treadmill combining BWS and FES of the common peroneal nerve in people following stroke. This study presented advantages in using that combination as improvements in motor skills, in spatial-temporal variables (stride duration, stance phase, cadence and gait symmetry), and the patients' preference due to the facilitation of the affected foot placement during walking.

However, the type of training surfaces used by patients is crucial, and this consideration may facilitate skills to be transfered into daily life activities ${ }^{10,17}$. Ground level is the most common locomotion surface and there are differences in several aspects between walking on treadmill and on ground level ${ }^{18}$. For example, the requirements for walking on treadmill differ from the requirements for walking on ground level in terms of propulsion and balance control ${ }^{19}$. In addition, the speed adopted to walk on treadmill is not self-selected as when walking on ground level ${ }^{18,20-23}$. Thus, walk on ground level could be more functional than on a treadmill, and presents a lower cost.

Considering these aspects, a recent study showed that the BWS system can also be used on ground level in stroke patients ${ }^{24}$. Moreover, similar to studies using a treadmill, a previous study conducted in our laboratory showed that the ground level gait training with BWS was also effective to improve some gait parameters ${ }^{25}$. Thus, it would be also interesting to evaluate the effect of a gait training conducted on ground level, combining BWS with FES in people with hemiparesis.

Therefore, the study hypothesis is that adding FES to a ground level gait training with BWS would promote additional gait improvements. Thus, the aim of this study was to investigate the effects of the addition of FES on the common peroneal nerve to a ground level gait training with BWS, on spatial-temporal gait parameters, segmental angles, and motor function in chronic stroke patients.

\section{Methods $\because:$.}

\section{Participants}

Twenty-nine chronic stroke patients were contacted, and 21 agreed to be evaluated. After the initial assessment, 16 subjects had conditions for inclusion in the study. Four of them did not complete the training protocol due to orthopedic complications $(n=3)$ and drop out $(n=1)$. Thus, 12 participants (4 women and 8 men, mean age: $53.8(\mathrm{SD}=7.5)$ years, time since injury: 41.7 (SD=34.3) months) have completed the study. Five subjects had right hemiparesis and 7 had left hemiparesis, due to ischemic $(\mathrm{n}=10)$ or hemorrhagic $(\mathrm{n}=2)$ brain injury from the median cerebral artery.

The study was approved by the Human Research Ethics Committee of Universidade Federal de São Carlos (UFSCar), São Carlos, SP, Brazil, and all subjects signed an informed consent form (approval number 364/2008-CEP/UFSCar).

\section{Clinical assessment}

Spasticity was examined by the Modified Ashworth Scale $(\mathrm{MAS})^{26}$, which levels ranged from 0 to 4; 0 represents no increase in muscle tone (velocity-dependent resistance to stretch), and 4 indicates a rigid joint in flexion or extension.

The walking capacity was assessed by Functional Ambulation Category $(\mathrm{FAC})^{27}$, which is based on a walking distance of $10 \mathrm{~m}$, and ranged from 0 to 5 . Level 0 describes people unable to walk or requiring the help of 2 or more people. At level 1 , people need continuous support of 1 person to help them carry their weight and maintain their balance. At level 2, people are dependent on continuous or intermittent support of 1 person to help with balance or coordination. At level 3, people need only verbal supervision. At level 4, help is required on stairs 
and uneven surfaces. Level 5 describes people who can walk independently in any given place.

Motor function was assessed through Rivermead Motor Assessment (RMA) ${ }^{28}$. This scale mixes impairments (on the arm, leg and trunk) and disabilities (gross function). The assessor goes through the items in order of difficulty and allows three attempts for each item. The score ranges from 0 to 13 for the gross function, 0 to 10 for the leg and trunk, and 0 to 15 for the arm.

The following inclusion criteria were considered: elapsed time since stroke longer than 6 months; spasticity classified under level 3 according to the MAS; ability to walk classified over level 1 according to the FAC. Patients with heart failure, angina pectoris, arrhythmias and other cardiovascular diseases, severe lung disease, orthopedic disorders, and severe cognitive or communication impairments were excluded.

Participants were submitted to clinical and gait evaluation protocols in the pre-training, and one day after the end of each training phase. Clinical evaluations through RMA and gait kinematics were performed on the same day, and the scale was applied before filming. The MAS and FAC was assessed only as an inclusion criterion. All scales were applied by the same assessor, who had a two-year experience in performing the tests.

\section{Gait assessment}

The gait kinematics assessments were conducted by two assessors at the Human Movement Analysis Laboratory, Department of Physical Therapy and Department of Physical Education and Human Motricity, UFSCar.

The participants were videotaped by 4 digital cameras ( $\mathrm{Pa}-$ nasonic, AG-DVC7P) at $60 \mathrm{~Hz}$, walking without BWS, at a selfselected comfortable speed, on a 10-meter rubberized walkway. They walked with shoes and without the assistance of orthesis or other devices. When necessary, they walked with the assistance of a physical therapist. The cameras were positioned bilaterally in order to allow kinematics measurements simultaneously in both directions of motion, and were synchronized by light shots. Passive reflective markers were attached by the same assessor in all evaluations, on the paretic and non-paretic body sides, at the following anatomical locations ${ }^{29}$ : head of the fifth metatarsal, lateral malleolus, lateral femoral epicondyle, greater trochanter, and acromion in order to define the foot, shank, thigh, and trunk segments, respectively.

Thereafter, the markers were digitized by using the software Ariel Performance Analysis System-APAS (Ariel Dynamics, Inc.) to acquire " $\mathrm{x}$ ", " $\mathrm{y}$ ", and " $\mathrm{z}$ " coordinates. Data were processed using Matlab software (version 6.5, Mathworks, Inc.). The data analysis was processed by four assessors, which always performed the same task for all evaluations and were previously trained.

\section{Gait training}

An $A_{1}-B-A_{2}$ study design was used, which $A_{1}$ and $A_{2}$ corresponded to a ground level gait training with BWS, and B corresponded to the same training combining FES. Each training phase was performed during 45 minutes, three times a week, on alternate days, for six weeks. Only one physical therapist trained the patients. They walked on a 10-meter rubberized walkway, only with the harness, and without the assistance of bars or other devices.

\section{Gait training with BWS (Phase A)}

The BWS system consisted of a harness ${ }^{19}$ with adjustable belts. The weight suspension was performed using a metal structure with a 10-meter tread with a pulley system and a steel cable. The engine drive regulated the cable length, lowering or raising the harness, which changed the body-weight relief percentage accordingly (see below).

The percentage of BWS was based on the participants' body mass $(\mathrm{kg})$. All participants started training with a $30 \%$ bodyweight relief5, which had been reduced along the training period. The criterion used to reduce the percentage of BWS was participants' ability to maintain the trunk alignment as well as to transfer the weight to the paretic limb ${ }^{13}$.

Verbal and manual corrections were made throughout the training: trunk vertical alignment, symmetrical weight bearing, lower-limb adequate movement, and upper-limb reciprocal oscillation. Participants were allowed to rest for some periods during each training session, according to their needs. In all sessions, heart rate and blood pressure were checked ${ }^{30}$. None of the patients received any other physical therapy intervention during the training period.

\section{FES (Phase B)}

A portable neuromuscular stimulator (Dorsiflex, AACD, SP, Brazil) was used to stimulate the common peroneal nerve of the paretic limb. The parameters of FES were symmetric biphasic square waves, with 150 microseconds, frequency of $25 \mathrm{~Hz}$, and intensity from 60 to $150 \mathrm{~V}$. The pulse intensity was regulated according to the participant's tolerance and the stimulation level needed to elicit effective muscle contraction.

The portable stimulator consists of a self-adhesive electrode pair that was placed on the motor point of the common peroneal nerve and on the paretic limb anterior tibialis muscular belly. A sensory insole, connected to the stimulator, was placed on the affected foot heel while a strap kept the stimulator attached to the paretic leg (Figure 1). FES was activated only in the swinging gait phase every time the individual started changing steps and it stopped every time the participant's foot touched the ground, avoiding muscle fatigue. 


\section{Data analysis}

RMA data were presented as a percentage of the total score for each domain. Regarding the kinematics variables, intermediate cycles of three gait repetitions were analyzed. The average of these cycles was calculated to obtain the mean cycle of each participant. The stride was determined from a foot contact to the floor until the next contact of the same foot to the floor along the progression line, and was defined visually. The following variables were analyzed: mean walking speed locomotion; step length; stride length, speed, and duration; initial and final double support duration; single-limb support duration; swing period; Range of Motion (ROM), maximum and minimum angles of the foot, leg, thigh, and trunk segments of both paretic and nonparetic limbs.

The "x" coordinate data (defined as movement progression plan) of the marker attached to the paretic and non-paretic

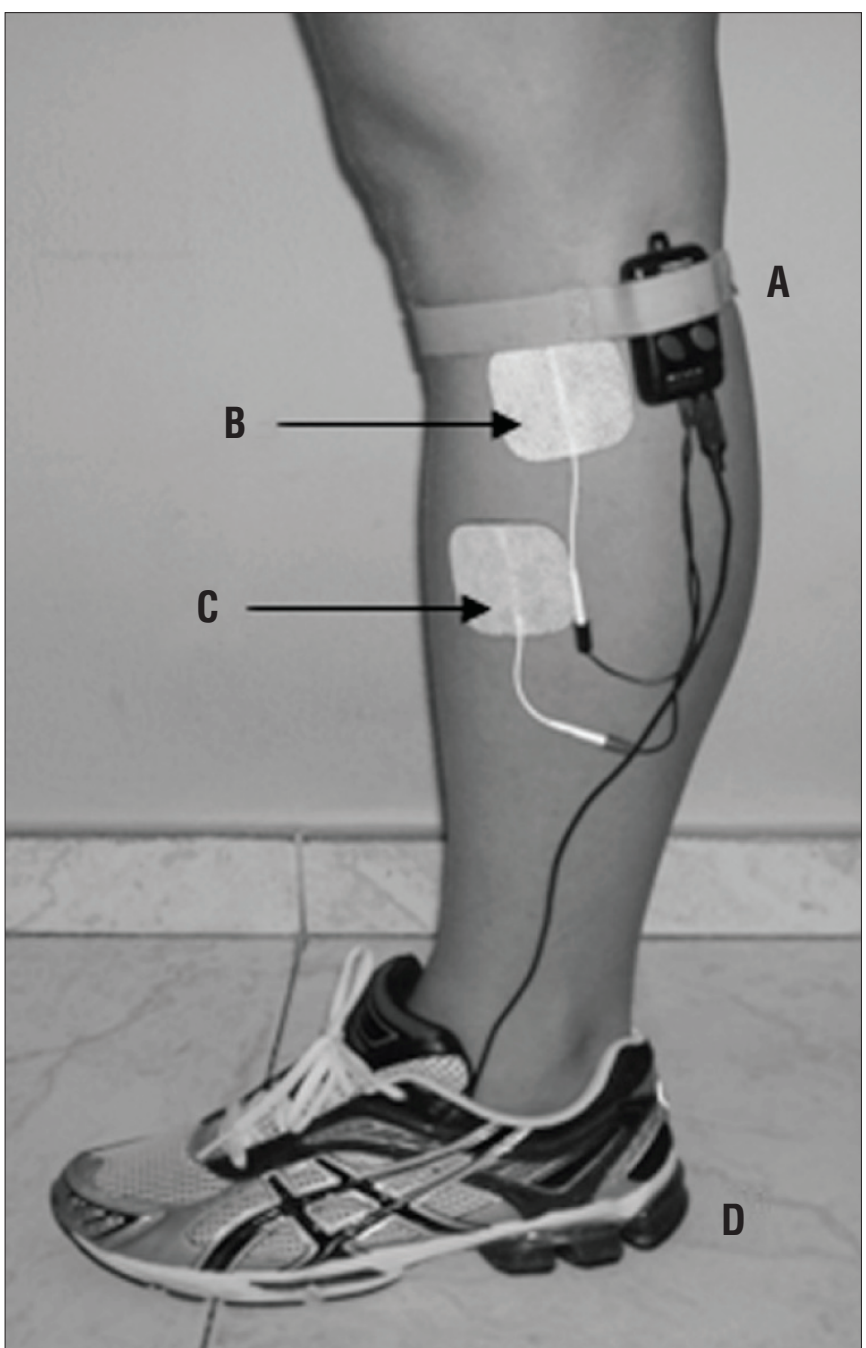

(A) Electronic stimulator. (B) Stimulation electrode placed at the motor point of the common peroneal nerve in the area between the popliteal fossa and the head of the fibula. (C) Electrode placed on the anterior tibialis belly. (D) Sensory insole located at the heel of the affected foot, inside the shoe.

Figure 1. Electrode positioning. lateral malleolus were used to calculate step and stride length, stride speed and duration, and support and balance duration. The step length was determined as the distance between the lateral malleolus markers of both limbs. The data of the same "x" coordinate of the greater trochanter marker were used to calculate the mean walking speed.

The segmental angles were calculated from the angle formed between a distal segment and an external horizontal plane, and the difference between the maximum and minimum values of the angles defined the ROMs.

\section{Statistical analysis}

Regarding RMA, Friedman and post hoc Dunn tests were applied. Regarding kinematics data, a two-way analysis of variance (ANOVA) and five multivariate analyses (MANOVA) were performed, using the two hemispheres (non-paretic and paretic) and the four assessments (pre-training, post- $\mathrm{A}_{1}$, post $B$, post- $A_{2}$ ) as factors treated as repeated measures. The dependent variables were: mean walking speed of locomotion for the first ANOVA, step length for the second ANOVA, stride length, speed, and duration for the first MANOVA, initial and final double support, single-limb support, and swing period durations for the second MANOVA; foot, leg, thigh, and trunk ROMs for the third MANOVA, and the minimum and maximum angles of these segments for the fourth and fifth MANOVAs, respectively. When necessary, post hoc Tukey test was applied. All tests were performed using the Statistical Package for the Social Sciences software (SPSS, version 10.0). A 0.05 alpha level was set.

\section{Results $\because \cdots$}

All participants were able to perform the required tasks in all experimental conditions. None of the participants required the use of orthesis during the training and the evaluations. Three of them needed help of a physical therapist to maintain balance during the data collection. In the pre-training evaluation, only one participant presented FAC at level one; eight participants presented FAC at level 2; one presented level 3; and two presented level 4. After the $\mathrm{A}_{1}$ phase, four participants improved one level. Three of them reached level 4, and one reached level 2. After the B phase, only one of them improved one level, reaching level 4. After the $\mathrm{A}_{2}$ phase, one participant increased one level, reaching level 3.

The relief percentage could be reduced in $10 \%$ of the body weight in relation to the previous phase. Only one of the subjects did not reach $0 \%$ of BWS at the end of training keeping it up to $10 \%$. 
RMA

Regarding RMA, although data presented a significant $p$ value at Friedman test $(\mathrm{p}=0.019)$ for trunk and lower limbs domain, the Dunn post hoc test did not identify differences among the assessments (Table 1).

\section{Spatial-temporal gait parameters}

The spatial-temporal gait parameters did not change after $B$ phase, when compared to the $A_{1}$ and $A_{2}$ phases. However, there was an increase in the mean walking speed after $A_{2}$ phase, from $0.39 \mathrm{~m} / \mathrm{s}$ to $0.55 \mathrm{~m} / \mathrm{s}$, when compared to the pretraining $(\mathrm{P}=0.02)$. The stride length increased for both paretic and nonparetic limbs after the $\mathrm{A}_{1}$ phase $(\mathrm{P}=0.03)$ and after the end of the $A_{2}(P=0.03)$. The stride speed also increased for both limbs when comparing the pre-training to the $\mathrm{A}_{2}$ phase $(\mathrm{P}=0.02)$. Differences between the paretic and nonparetic limbs were observed in the swing period $(\mathrm{P}<0.001)$ and in the singlelimb support $(\mathrm{P}<0.001)$, which persisted until the training final phase (Table 2).

\section{Segmental angles}

The segmental angles parameters did not also change after $B$ phase, when compared to the $A_{1}$ and $A_{2}$ phases. However, regarding the ROMs, the leg showed an increased ROM when comparing the pre-training to the $\mathrm{A}_{1}$ phase $(\mathrm{P}=0.03)$. For the thigh, the ROM increased when comparing the pre-training to the $\mathrm{A}_{1}(\mathrm{P}=0.003)$ and the $\mathrm{A}_{2}$ phases $(\mathrm{P}=0.008)$. Paretic and nonparetic limbs were different for foot $(\mathrm{P}<0.001)$, leg $(\mathrm{P}<0.001)$, and trunk segments $(\mathrm{P}<0.001)$ in the pre-training evaluation, which lasted until the end of the $\mathrm{A}_{2}$ phase (Table 3 ).

Regarding the maximum segmental angle, the thigh segment showed differences between the paretic and nonparetic limbs in the pre-training evaluation $(\mathrm{P}=0.006)$, which lasted until the $A_{2}$ phase. The thigh maximum segmental angle increased only in the paretic limb when comparing the pretraining to the $\mathrm{A}_{1}$ phase $(\mathrm{P}=0.04)$. Regarding the minimum segmental angle, the paretic and nonparetic limbs were different for foot $(\mathrm{P}=0001)$, leg $(\mathrm{P}=0.001)$, thigh $(\mathrm{P}=0.04)$, and trunk $(\mathrm{P}=0.002)$ in the pre-training evaluation, which lasted until the $\mathrm{A}_{2}$ phase (Table 3).

Table 1. Gait and functional activities evaluation before and after the three phases of ground level gait training combining BWS and FES.

\begin{tabular}{lcccc}
\hline & Pre-training & Post-phase $\mathrm{A}_{1}$ & Post-phase B & ${\text { Post-phase } \mathrm{A}_{2}}$ \\
\hline Rivermead general function (\%) & $84.62(23.08)$ & $84.62(15.39)$ & $84.62(15.39)$ & $84.62(15.39)$ \\
\hline Rivermead trunk and lower limbs (\%) & $60(80)$ & $60(80)$ & $70(60)$ & $70(50)$ \\
\hline Rivermead upper limbs (\%) & $6.67(86.67)$ & $6.67(86.67)$ & $6.67(86.67)$ & $6.67(86.67)$ \\
\hline
\end{tabular}

Values are reported as median percentages range. $A_{1}$ e $A_{2}=$ ground level gait training with $B W S ; B=$ ground level gait training combining $B W S$ and FES.

Table 2. Spatial and temporal gait parameters of the paretic and non-paretic limbs before and after the three phases of ground level gait training combining BWS and FES.

\begin{tabular}{|c|c|c|c|c|c|}
\hline Outcome measures & Limb & Pre-training & Post-phase $A_{1}$ & Post-phase B & Post-phase $\mathrm{A}_{2}$ \\
\hline Mean walking speed (m/s) & & $0.39(0.2)^{\mathrm{a}}$ & $0.52(0.3)$ & $0.52(0.3)$ & $0.55(0.3)^{a}$ \\
\hline \multirow{2}{*}{ Step length $(\mathrm{m})$} & Nonparetic & $0.33(0.1)$ & $0.39(0.1)$ & $0.38(0.1)$ & $0.38(0.1)$ \\
\hline & Paretic & $0.32(0.1)$ & $0.35(0.1)$ & $0.35(0.2)$ & $0.36(0.2)$ \\
\hline \multirow[t]{2}{*}{ Stride length $(\mathrm{m})$} & Nonparetic & $0.62(0.1)^{\mathrm{ab}}$ & $0.75(0.2)^{\mathrm{a}}$ & $0.73(0.2)$ & $0.74(0.2)^{b}$ \\
\hline & Paretic & $0.63(0.1)^{\mathrm{ab}}$ & $0.76(0.2)^{\mathrm{a}}$ & $0.74(0.2)$ & $0.75(0.2)^{b}$ \\
\hline \multirow[t]{2}{*}{ Stride speed (m/s) } & Nonparetic & $0.38(0.2)^{a}$ & $0.50(0.3)$ & $0.50(0.3)$ & $0.53(0.3)^{\mathrm{a}}$ \\
\hline & Paretic & $0.39(0.2)^{\mathrm{a}}$ & $0.51(0.3)$ & $0.51(0.3)$ & $0.54(0.3)^{\mathrm{a}}$ \\
\hline \multirow[t]{2}{*}{ Stride duration (s) } & Nonparetic & $1.8(0.7)$ & $1.8(0.7)$ & $1.7(0.6)$ & $1.6(0.5)$ \\
\hline & Paretic & $1.9(0.8)$ & $1.8(0.7)$ & $1.7(0.6)$ & $1.5(0.4)$ \\
\hline \multirow[t]{2}{*}{ Initial double support (\%) } & Nonparetic & $25.6(8.5)$ & $23.5(9.3)$ & $23.4(9.3)$ & $22.8(7.9)$ \\
\hline & Paretic & $22.2(13.1)$ & $21.1(11.8)$ & $21.3(11.9)$ & $19.6(9.1)$ \\
\hline \multirow[t]{2}{*}{ Single support (\%) } & Nonparetic & $32.9(8.3)$ & $33.6(9.0)$ & $32.9(10.1)$ & $34.4(8.7)$ \\
\hline & Paretic & $18.6(6.6)^{\star}$ & $21.1(7.6)^{\star}$ & $21.1(7.1)^{\star}$ & $21.5(5.9)^{\star}$ \\
\hline \multirow[t]{2}{*}{ Final double support (\%) } & Nonparetic & $21.8(10.2)$ & $20.9(11.2)$ & $21.8(12.1)$ & $19.9(9.6)$ \\
\hline & Paretic & $25.4(8.7)$ & $23.3(9.3)$ & $23.6(9.9)$ & $23.1(7.9)$ \\
\hline \multirow[t]{2}{*}{ Swing period (\%) } & Nonparetic & $19.6(6.4)$ & $21.9(7.6)$ & $21.8(7.3)$ & $22.8(6.2)$ \\
\hline & Paretic & $33.8(9.3)^{*}$ & $34.4(9.5)^{\star}$ & $33.9(10.0)^{\star}$ & $35.7(8.6)^{\star}$ \\
\hline
\end{tabular}

Values are reported as mean and standard deviation: M (SD); * Represent significant differences between limbs; same letters (a, b) indicates significant differences between evaluations; $A_{1}$ e $A_{2}=$ ground level gait training with BWS; $B=$ ground level gait training combining BWS and FES. 
Figure 2 shows the mean (SD) stride cycle of segmental angle patterns in the four evaluations. Qualitatively, the segments showed a similar pattern throughout the four evaluations, having marked temporal differences between limbs. The nonparetic foot showed greater and later posterior displacement in the cycle when comparing to the paretic limb in all evaluations. The same behavior was observed for the leg segment.

\section{Discussion $\because \because$.}

In general, an improvement on functional gait was observed after 18 weeks of training. The present study did not find improvements for the RMA score. The lack of positive findings could be attributed to a gait training specificity, which could not be able to transfer the gains to the daily activities.

Regarding spatial-temporal variables and segmental angles, the addition of FES did not change these parameters. The lack of positive findings differs from a series of studies. Pomeroy et al. ${ }^{31}$ reported findings in favor of FES in comparisons between people with hemiparesis that were not receiving any other treatment. Moreover, according to Yavuzer et al..$^{32}$, there is not a recommended standardized consensus about FES duration or daily stimulation time, that could have also explain the lack of positive findings.
On the other hand, Lindquist et al. ${ }^{13}$ evaluated FES combining treadmill training with BWS in chronic stroke patients. Their research design was the same $\left(\mathrm{A}_{1}-\mathrm{B}-\mathrm{A}_{2}\right)$; however they identified gait functional benefits. Their training duration was three weeks in each phase, whereas in the present study the training took place during six weeks. Perhaps the grater training volume in the $\mathrm{A}_{1}$ phase had been enough to lead participants to reach a gait adaptation plateau. Moreover, gait training on a treadmill requires different demands regarding the propulsion and balance controls, compared to walking on ground level. Although the participants's functional level in the present study is more heterogeneous than the study of Lindquist, we do not think that FES benefits only patients with similar functional levels.

In the present study, it was possible to verify that 18 weeks of training changed some gait parameters as mean walking speed, stride length and speed, probably due to the reduction of BWS relief, which requires more voluntary propulsion. These findings may also be attributed to an accumulated training effect.

The mean walking speed of locomotion is widely used to analyze the functional ability, and it is an important indicator of motor recovery ${ }^{3,33}$. The increase in the mean walking speed of locomotion may be attributed to an increased stride length and speed for both limbs. This probably may have occurred by an improvement in the hip flexor muscle activation pattern

Table 3. Segmental angles of the paretic and non-paretic limbs before and after the three phases of ground level gait training combining BWS and FES.

\begin{tabular}{|c|c|c|c|c|c|c|}
\hline Segment & Outcome measures $\left({ }^{\circ}\right)$ & Limb & Pre-training & Post-phase $A_{1}$ & Post-phase B & Post-phase $\mathrm{A}_{2}$ \\
\hline \multirow[t]{6}{*}{ Foot } & Maximum angle & Nonparetic & $9.0(4.2)$ & $11.3(7.6)$ & $10.6(7.1)$ & $11.3(6.5)$ \\
\hline & & Paretic & $7.1(5.5)$ & $9.0(5.1)$ & $9.2(6.8)$ & $9.2(5.9)$ \\
\hline & Minimum angle & Nonparetic & $-49.1(9.5)$ & $-54.6(11.6)$ & $-54.1(10.9)$ & $-54.0(10.3)$ \\
\hline & & Paretic & $-31.3(14.6)^{\star}$ & $-35.3(12.8)^{\star}$ & $-34.4(11.3)^{\star}$ & $-34.4(12.1)^{\star}$ \\
\hline & ROM & Nonparetic & $58.2(12.9)$ & $65.9(16.5)$ & $64.7(16.5)$ & $65.3(15.1)$ \\
\hline & & Paretic & $38.6(15.8)^{\star}$ & $44.3(14.9)^{*}$ & $43.5(15.1)^{\star}$ & $43.6(13.1)^{\star}$ \\
\hline \multirow[t]{6}{*}{ Leg } & Maximum angle & Nonparetic & $13.4(5.7)$ & $15.6(6.2)$ & $14.8(8.0)$ & $14.6(7.5)$ \\
\hline & & Paretic & $12.6(4.9)$ & $13.5(4.8)$ & $12.8(5.7)$ & $12.7(5.6)$ \\
\hline & Minimum angle & Nonparetic & $-36.6(6.5)$ & $-39.3(5.9)$ & $-39.6(6.3)$ & $-40.2(5.9)$ \\
\hline & & Paretic & $-21.4(10.5)^{\star}$ & $-25.9(9.2)^{\star}$ & $-25.4(9.9)^{\star}$ & $-26.4(8.7)^{\star}$ \\
\hline & ROM & Nonparetic & $50.1(8.1)^{\mathrm{a}}$ & $54.9(9.7)^{\mathrm{a}}$ & $54.4(10.9)$ & $54.8(9.9)$ \\
\hline & & Paretic & $33.9(11.7)^{\star a}$ & $39.4(11.5)^{*_{a}}$ & $38.3(12.5)^{*}$ & $39.1(10.7)^{*}$ \\
\hline \multirow[t]{6}{*}{ Thigh } & Maximum angle & Nonparetic & $27.4(4.2)$ & $29.1(3.1)$ & $27.8(3.3)$ & $29.1(1.8)$ \\
\hline & & Paretic & $19.4(6.0)^{\star a}$ & $24.3(5.7)^{\star a}$ & $25.0(6.3)^{\star}$ & $24.6(4.3)^{\star}$ \\
\hline & Minimum angle & Nonparetic & $-3.5(4.8)$ & $-5.7(5.2)$ & $-5.4(5.7)$ & $-5.4(4.7)$ \\
\hline & & Paretic & $-8.3(5.6)^{\star}$ & $-8.8(5.4)^{\star}$ & $-7.1(6.2)^{\star}$ & $-7.7(7.2)^{*}$ \\
\hline & ROM & Nonparetic & $30.9(4.8)^{\mathrm{ab}}$ & $35.1(6.8)^{\mathrm{a}}$ & $34.2(6.8)$ & $34.5(5.2)^{b}$ \\
\hline & & Paretic & $27.7(6.4)^{\mathrm{ab}}$ & $33.1(8.6)^{\mathrm{a}}$ & $32.2(9.2)$ & $32.4(7.7)^{b}$ \\
\hline \multirow[t]{6}{*}{ Trunk } & Maximum angle & Nonparetic & $-0.6(4.9)$ & $1.0(5.4)$ & $-0.6(4.0)$ & $0.5(4.1)$ \\
\hline & & Paretic & $2.0(3.6)$ & $2.5(3.9)$ & $2.2(3.1)$ & $3.9(3.4)$ \\
\hline & Minimum angle & Nonparetic & $-8.8(4.2)$ & $-8.1(4.5)$ & $-8.9(3.8)$ & $-7.3(4.2)$ \\
\hline & & Paretic & $-10.7(4.2)^{\star}$ & $-12.0(5.6)^{\star}$ & $-12.3(4.5)^{\star}$ & $-10.5(4.8)^{\star}$ \\
\hline & ROM & Nonparetic & $8.2(2.4)$ & $9.1(3.1)$ & $8.3(2.4)$ & $7.8(2.1)$ \\
\hline & & Paretic & $12.7(2.5)^{\star}$ & $14.6(3.7)^{\star}$ & $14.6(3.2)^{\star}$ & $14.4(3.6)^{\star}$ \\
\hline
\end{tabular}

Values are reported as mean and standard deviation: $\mathrm{M}(\mathrm{SD}) ;{ }^{*}$ Represent significant differences between limbs; same letters $(\mathrm{a}, \mathrm{b})$ indicates significant differences between evaluations; $A_{1}$ e $A_{2}=$ ground level gait training with BWS; $B$ = ground level gait training combining BWS and FES. 

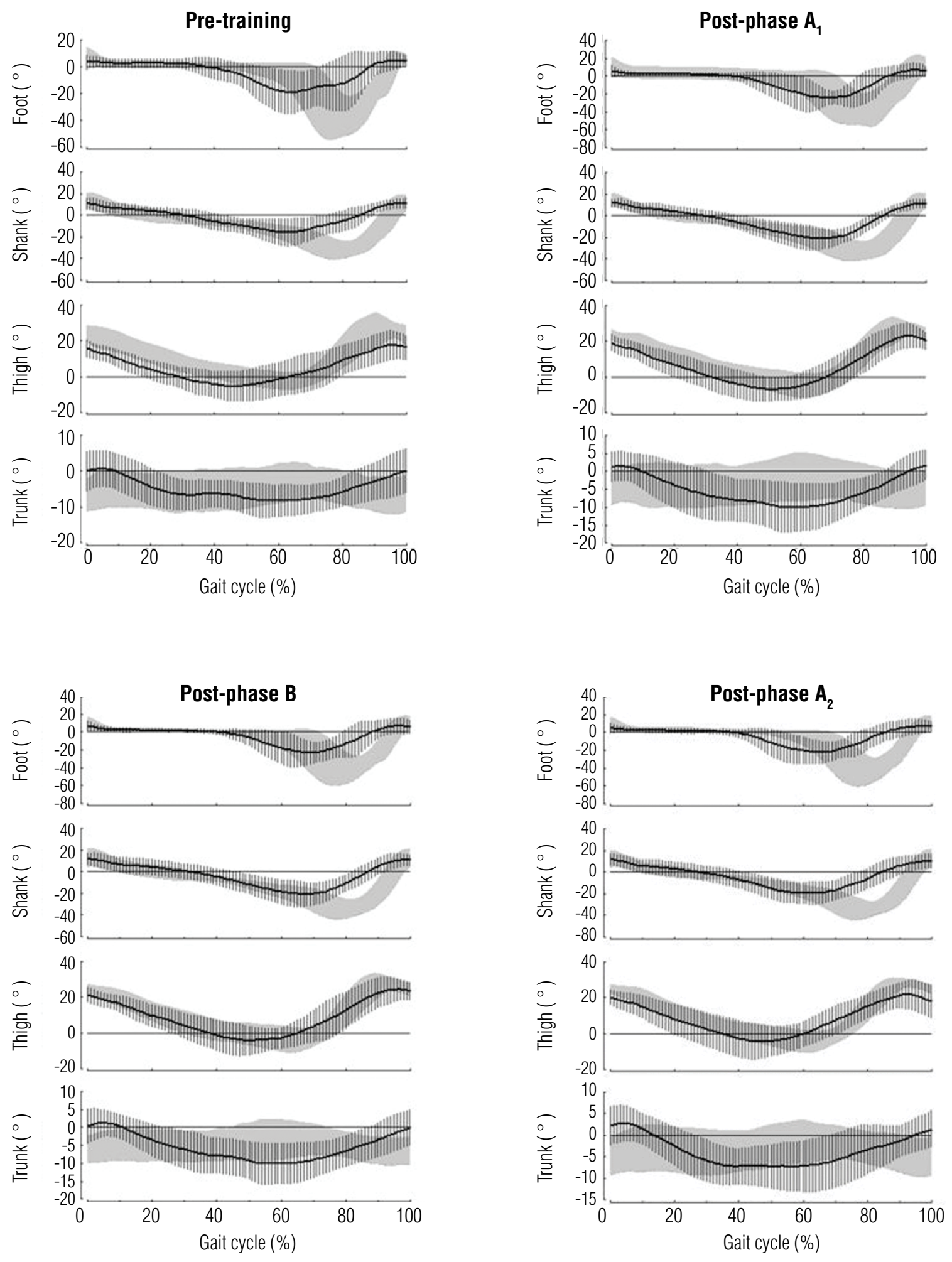

- Paretic

Nonparetic

Figure 2. Foot, leg, thigh, and trunk segmental angles during the stride cycle. Mean (SD) stride cycle of foot, shank, thigh, and trunk segmental angles for the people following chronic stroke in the pre-training, post-phase $A_{1}$, post-phase B, and post-phase $A_{2}$ of the nonparetic (gray area) and paretic (line) body sides. $A_{1}$ e $A_{2}=$ ground level gait training with $B W S ; B=$ ground level gait training combining BWS and FES. Positive values denote counter-clockwise (backward) rotation of segments and negative values denote clockwise (forward) rotation of segments. 
and the energy generation in the paretic limb, especially in the final supporting period, which is essential to lead the limb forward and to control the displacement speed ${ }^{34}$. These changes are clinically important because they reflect and contribute to the patients' autonomy.

The 18 weeks of training also provided a better lower-limb voluntary motor response, since the training increased the thigh segmental ROM. This result is important since the lower limb proximal control has been considered to be determinant for a comfortable gait speed ${ }^{35}$. However, it is important to reduce the percentage of BWS relief in order to increase the lower-limb distal muscle activation ${ }^{36}$ and to improve motor control $^{37}$.

Aside from these improvements, the training protocol did not change the gait cycle temporal organization asymmetry and segmental angles, which is a discriminating factor in patients with stroke ${ }^{38}$. Harris-Love et al. ${ }^{20}$ found that patients with chronic stroke presented different durations of single stance and stance/swing ratios between paretic and nonparetic limbs even during treadmill walking.

Regarding the temporal series qualitative analysis, the study showed that the FES was not able to change the segments behaviors. The nonparetic foot showed greater and later posterior displacement in the cycle when compared to the paretic limb throughout the four assessments. The same behavior was observed for the leg segment, which impaired the knee flexion during the swinging phase. That occurred probably due to anticipation in the paretic limb propulsion phase as a consequence of the support positive reaction activation, a common reflex mechanism in stroke patients ${ }^{39}$. Thus, the addition of FES was not able to avoid the support positive reaction, or to promote the paretic limb dorsiflexion.

This asymmetric pattern may be considered a compensatory strategy to propel the paretic limb forward. Thus, the participants did not improve these gait characteristics because they were in a chronic recovery stage, which contributed to a consolidated gait pattern ${ }^{3}$.

This study has some limitations. One factor was that a statistical power was not calculated and a small number of subjects were recruited. Another limitation was the possibility of a carryover or sequence effect from one phase to the next. However, the $\mathrm{A}_{1}-\mathrm{B}-\mathrm{A}_{2}$ design allowed for the evaluation of the same subject during different procedures. Furthermore, this design had been chosen in previous investigations ${ }^{9,13}$. Moreover, is also important to compare the two types of surfaces (treadmill and ground level) with the same phase durations in future studies.

Despite a number of limitations, this study brought contributions and is a pioneer in analyzing the effects of ground level gait training combining BWS with FES post-stroke. Participants themselves reported security improvement in relation to their balance, and that the training was intense in relation to their daily activities. These important aspects motivated the patients to participate with a high level of adherence. We consider a high level of adherence, since only one of the 16 selected volunteers dropped out from treatment. In addition, patients rarely had to miss, and the absences were always replaced on weekends. Furthermore, the BWS system is safe and has a low cost. The training is easy to be implemented in clinical practice, and only one physical therapist is necessary to train the patients. In conclusion, the addition of FES to the ground level gait training with BWS did not provide any additional improvement in gait parameters.

\section{Acknowledgement $: \because$.}

The patients for their participation, to the Conselho Nacional de Desenvolvimento Científico e Tecnológico (CNPq), Brazil for the financial support, Master and a Post-Doctor scholarships, and to Fundação de Amparo a Pesquisa do Estado de São Paulo (FAPESP), Brazil for the PhD scholarship.

\section{References $: \because 8$.}

1. World Health Organization. Who Steps Stroke Manual: the Who Stepwise approach to stroke surveillance/Noncommunicable Diseases and Mental Health, World Health Organization, 2006. [Updated 2006 Aug 26]. Available from: http://www.who.int/chp/steps/Stroke/en/

2. Pontes-Neto OM, Silva GS, Feitosa MR, de Figueiredo NL, Fiorot JAJr, Rocha TN, et al. Stroke awareness in Brazil: alarming results in a community-based study. Stroke. 2008;39(2):292-6.

3. Olney SJ, Richards C. Hemiparetic gait following stroke. Part I: characteristics. Gait Posture. 1996:4(2):136-48.

4. Visintin M, Barbeau $\mathrm{H}$, Korner-Bitensky N, Mayo NE. A new approach to retrain gait in stroke patients through body weight support and treadmill stimulation. Stroke. 1998;29(6):1122-8.

5. Hesse S, Konrad M, Uhlenbrock D. Treadmill walking with partial body weight support versus floor walking in hemiparetic subjects. Arch Phys Med Rehabil. 1999;80(4):421-7.

6. Hesse S, Werner C, von Frankenberg S, Bardeleben A. Treadmill training with partial body weight support after stroke. Phys Med Rehabil Clin N Am. 2003;14(1 Suppl):S111-23.
7. Barbeau H, Visintin M. Optimal outcomes obtained with body-weight support combined with treadmill training in stroke subjects. Arch Phys Med Rehabil. 2003;84(10):1458-65.

8. van Hedel HJ, Tomatis L, Müller R. Modulation of leg muscle activity and gait kinematics by walking speed and bodyweight unloading. Gait Posture. 2006;24(1):35-45.

9. Hesse S, Malezic M, Schaffrin A, Mauritz KH. Restoration of gait by combined treadmill training and multichannel electrical stimulation in non-ambulatory hemiparetic patients. Scand J Rehabil Med. 1995;27(4):199-204

10. Barbeau H, Lamontagne A, Ladouceur M, Mercier I, Fung J. Optimizing locomotor function with body weight support training and functional electrical stimulation. In: Latash ML, Levin MF, eds. Progress in motor control. Champaign (IL): Human Kinetics; 2004. p. 237-51.

11. Daly JJ, Ruff RL. Feasibility of combining multi-channel functional neuromuscular stimulation with weight-supported treadmill training. J Neurol Sci. 2004;225(1-2):105-15.

12. Daly JJ, Roenigk KL, Butler KM, Gansen JL, Fredrickson E, Marsolais EB, et al. Response of 
sagittal plane gait kinematics to weight-supported treadmill training and functional neuromuscular stimulation following stroke. J Rehabil Res Dev. 2004;41(6A):807-20.

13. Lindquist AR, Prado CL, Barros RM, Mattioli R, Costa PHL, Salvini TF. Gait training combining partial body-weight support, a treadmill, and functional electrical stimulation: effects on poststroke gait. Phys Ther. 2007;87(9):1144-54.

14. Liberson WT, Holmquest HJ, Scot D, Dow M. Functional electrotherapy: stimulation of the peroneal nerve synchronized with the swing phase of the gait of hemiplegic patients. Arch Phys Med Rehabil. 1961;42:101-5.

15. Chae J, Yu D. A critical review of neuromuscular electrical stimulation for treatment of motor dysfunction in hemiplegia. Assist Technol. 2000;12(1):33-49.

16. Soetanto D, Kuo CY, Babic D. Stabilization of human standing posture using functional neuromuscular stimulation. J Biomech. 2001;34(12):1589-97.

17. Matsas A, Taylor N, McBurney H. Knee joint kinematics from familiarised treadmill walking can be generalised to overground walking in young unimpaired subjects. Gait Posture. 2000;11(1):4653

18. Alton F, Baldey L, Caplan S, Morrissey MC. A kinematic comparison of overground and treadmill walking. Clin Biomech (Bristol, Avon). 1998;13(6):434-40.

19. Norman KE, Pepin A, Ladouceur M, Barbeau H. A treadmill apparatus and harness support for evaluation and rehabilitation of gait. Arch Phys Med Rehabil. 1995;76(8):772-8.

20. Harris-Love ML, Macko RF, Whitall J, Forrester LW. Improved hemiparetic muscle activation in treadmill versus overground walking. Neurorehabil Neural Repair. 2004;18(3):154-60.

21. Bayat $\mathrm{R}$, Barbeau $\mathrm{H}$, Lamontagne A. Speed and temporal-distance adaptations during treadmill and overground walking following stroke. Neurorehabil Neural Repair. 2005;19(2):115-24.

22. Warabi T, Kato M, Kiriyama K, Yoshida T, Kobayashi N. Treadmill walking and overground walking of human subjects compared by recording sole-floor reaction force. Neurosci Res. 2005;53(3):343-8

23. Lee SJ, Hidler J. Biomechanics of overground vs. treadmill walking in healthy individuals. J Appl Physiol. 2008;104(3):747-55

24. Sousa CO, Barela JA, Prado-Medeiros CL, Salvini TF, Barela AM. The use of body weight support on ground level: an alternative strategy for gait training of individuals with stroke. J Neuroeng Rehabil. 2009;6:43.

25. Sousa CO, Prado CL, Salvini TF, Barela AMF. Efeitos do treinamento de marcha em pacientes hemiparéticos com suporte parcial de peso corporal em piso fixo. In: Brazilian Journal of Motor Behavior. 2008: Proceedings of the IV Congresso Brasileiro de Comportamento Motor, 2008, São Paulo. Porto Alegre: Brazilian Society of Motor Behavior; 2008;3:6
26. Bohannon RW, Smith MB. Interrater reliability of a modified Ashworth scale of muscle spasticity Phys Ther. 1987;67(2):206-7.

27. Wade DT. Measurement in neurological rehabilitation. New York, NY: Oxford University Press 1992.

28. Collen FM, Wade DT, Bradshaw CM. Mobility after stroke: reliability of measures of impairment and disability. Int Disabil Stud. 1990;12(1):6-9.

29. Patiño MS, Gonçalves AR, Monteiro BC, Santos IL, Barela AMF, Barela JA. Características cinemáticas, cinéticas e eletromiográficas do andar de adultos jovens com e sem suporte parcial de peso corporal. Rev Bras Fisioter. 2007;11(1):19-25

30. Pickering TG, Hall JE, Appel LJ, Falkner BE, Graves J, Hill MN, et al. Recommendations for blood pressure measurement in humans and experimental animals: Part 1: blood pressure measurement in humans. A statement for professionals from the Subcommittee of Professional and Public Education of the American Heart Association Council on High Blood Pressure Research. Hypertension. 2005;45(1):142-61.

31. Pomeroy VM, King L, Pollock A, Baily-Hallam A, Langhorne P. Electrostimulation for promoting recovery of movement or functional ability after stroke. Cochrane Database Syst Rev. 2006;(2):CD003241.

32. Yavuzer G, Öken Ö, Atay MB, Stam HJ. Effect of sensory-amplitude electric stimulation on motor recovery and gait kinematics after stroke: a randomized controlled study. Arch Phys Med Rehabil. 2007;88(6):710-4.

33. Wall JC, Turnbull Gl. Gait asymmetries in residual hemiplegia. Arch Phys Med Rehabil 1986;67(8):550-3.

34. Riley PO, Della Croce U, Kerrigan DC. Propulsive adaptation to changing gait speed. J Biomech. 2001;34(2):197-202

35. Chen CL, Chen HC, Tang SF, Wu CY, Cheng PT, Hong WH. Gait performance with compensatory adaptations in stroke patients with different degrees of motor recovery. Am J Phys Med Rehabil. 2003;82(12):925-35

36. Peurala SH, Tarkka IM, Pitkänen K, Sivenius J. The effectiveness of body weight-supported gait training and floor walking in patients with chronic stroke. Arch Phys Med Rehabil 2005;86(8):1557-64.

37. Sullivan KJ, Knowlton BJ, Dobkin BH. Step training with body weight support: effect of treadmil speed and practice paradigms on poststroke locomotor recovery. Arch Phys Med Rehabil. 2002;83(5):683-91.

38. Hodt-Billington C, Helbostad JL, Moe-Nilssen R. Should trunk movement or footfall parameters quantify gait asymmetry in chronic stroke patients? Gait Posture. 2008;27(4):552-8.

39. Perry J. Gait analysis: normal and pathological function. New York, NY: McGraw-Hill; 1992. 